\title{
Correlation of Operative Time with Outcomes of Ureteroscopy and Stone Treatment: a Systematic Review of Literature
}

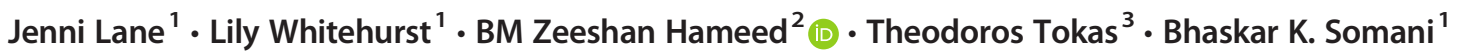

Published online: 24 March 2020

(C) The Author(s) 2020

\begin{abstract}
Purpose of Review To present the latest evidence related to the impact of increased operative times in retrograde intrarenal surgery and identify possible important factors that can facilitate ureteroscopy procedures.

Recent Findings Ureteroscopy constitutes the mainstay treatment of renal stones and is characterized by a huge variation in techniques and instrumentation. It has been suggested that increased operative times can mitigate the outcomes of the procedures by increasing complication rates. Nevertheless, little is known about the time limits, above which complications are likely to occur. Furthermore, complication rates in different procedure durations have not yet been assessed.

Summary Prolonged operative times are linked to increased complication rates in ureteroscopy. Stone complexity, patient risk factors, surgeon experience, bilateral surgery, and instrumentation constitute important factors that can hamper or facilitate a procedure and should be taken into account beforehand. Keeping procedural times below $90 \mathrm{~min}$ can dissuade potential predicaments and achieve improved stone-free rates.
\end{abstract}

Keywords Operative time $\cdot$ Ureteroscopy $\cdot$ Retrograde intrarenal surgery $\cdot$ Procedure time $\cdot$ Stone $\cdot$ Complication

\section{Introduction}

Ureteroscopy (URS) is a safe and effective method of treating ureteric and renal stones, and over the past two decades, the number of URS procedures performed has increased by $252 \%$ $[1,2]$. The increase in kidney stone disease (KSD) has been

This article is part of the Topical Collection on Endourology

Bhaskar K. Somani

bhaskarsomani@yahoo.com; b.k.somani@soton.ac.uk

Jenni Lane

jennilane@doctors.org.uk

Lily Whitehurst

lilywhitehurst1@hotmail.co.uk

BM Zeeshan Hameed

zeeshanhameedbm@gmail.com

Theodoros Tokas

ttokas@yahoo.com

1 University Hospital Southampton NHS Trust, Southampton, UK

2 Kasturba Medical College, Manipal, India

3 Department of Urology and Andrology, General Hospital Hall in Tirol, Hall in Tirol, Austria due to a combination of factors including global warming, more incidental stones diagnosed on CT scan, and metabolic syndrome $[3,4,5 \cdot]$. The European Association of Urologists (EAU) guidelines have an algorithm for the treatment of stone disease to aid clinicians in their decision-making for the choice of surgical option [6].

Ureteroscopy is now being used for a wide variety of treatment conditions, and its role has expanded [6-9]. As such, endourologists have audited the outcomes in an attempt to lower their complication rates. A number of factors make surgery more challenging and can have an impact on clinical outcomes. These include stone size and location, multiplicity, patient comorbidities, and surgeon experience. All these factors have an effect on the operative time which in turn can influence patient outcome [10-20].

Whilst the operating time is affected by patient and stonerelated factors, it is also influenced by other factors such as the presence of preoperative stent, use of a ureteral access sheath (UAS), surgery for bilateral stones, the type of ureteroscope used, use of fluoroscopy, and surgeon experience [13, 16, 17, 21-28]. Previously other studies in joint replacement surgeries, laparoscopic procedures, and percutaneous nephrolithotomy (PCNL) showed better outcomes with reduced operative time duration [29-31]. 
We present the results of our systematic review looking at the correlation of operative times with the outcomes of ureteroscopy and stone treatment.

\section{Methods}

\section{Evidence Acquisition}

\section{Inclusion Criteria}

1. Studies which recorded operative times of ureteroscopy and stone treatment and correlated it with complications of the procedure

2. Articles written in English language

\section{Exclusion}

1. Paediatric studies

2. Animal or laboratory studies

3. Case reports or review articles

4. Older studies using the same data as a more recent study where the longest follow-up was included

The systematic review was performed according to the Cochrane review guidelines [32] and in accordance with the Preferred Reporting Items for Systematic Reviews and Metaanalyses (PRISMA) checklist [33].

The search strategy was conducted to find relevant studies from the Medline, EMBASE, Cochrane Library, CINAHL, Clinicaltrials.gov, and Google Scholar. The search terms included 'ureteroscopy', 'URS', 'Retrograde intrarenal surgery', 'RIRS', 'endoscopic', 'operative time', 'procedure time', 'laser', 'stone', 'calculi', 'mortality', 'complication', and 'death'. Boolean operators (AND, OR) were used to refine the search. Two experienced reviewers identified all studies (JL, LW). All studies that appeared to fit the inclusion criteria were included for full review. Each reviewer independently selected studies for inclusion in the review, and discrepancies were resolved by consensus with the senior author (BKS).

The search was limited to English language articles between 1999 and 2019; a cut-off of 10 patients was set per study to include centres with the minimum relevant endourological experience, and where more than one article was related to the same study, the longest follow-up was included.

\section{Data Extraction and Analysis}

Data was extracted for year of publication, study type, stonefree rate (SFR), sample size, age, stone size, complications, and operative time. Data was collated using Microsoft Excel (version 12.2.4).

\section{Results}

After initial screening of 680 articles, 197 abstracts were assessed for eligibility. Eventually, 8 studies met our inclusion criteria and were then included in our final analysis. Full details of the search results are depicted in the PRISMA diagram in Fig. 1.

Overall there were 32,283 patients included in the review (Table 1). All but one study [21-27] provided the mean ages of their patients, with their cumulative mean age being 50.1 years. There was a male to female predominance with 20,518 males to 11,730 females. The majority of studies provided stone size and location details [21-24, 26]. Two studies focused solely on renal stones $[22,23]$. Three groups presented mean stone volumes $\left(161.3-934.6 \mathrm{~mm}^{3}\right)$ [22, 23, 26], two mean maximal stone diameters (7-9.3 $\mathrm{mm}$; range $2.3-22 \mathrm{~mm}$ ) $[21,24]$, and three did not present any information about stone size $[25,27,28]$.

Stone-free rates were recorded in five studies [21, 22, 24, $26,27]$ with an average SFR of $84 \%$. Only three studies explained their method for determining SFR. Ozgor et al. determined SFR by repeating an abdominal CT in 1-3 months to ensure it was absent of residual fragments [26]. Knipper et al. assessed SFR with a renal ultrasound post-operatively on day one to determine the absence of hydronephrosis and/or residual stones, whereas Elashery et al. performed a plain X-ray immediately post-operatively [21, 24].

Half of the included studies categorized patients into groups depending on whether they had encountered operative complications [22, 25-27]. Their average operative time in patients who had encountered complications was $64.9 \mathrm{~min}$ versus $48.7 \mathrm{~min}$ in those without complications. All but one study [23] identified a significant link between operative time and complication rates $(p=<0.001)$. Sugihara et al. [28] classified the operative times into seven categories; they found that with increasing operative times, complication rates increased. Their maximum operative time at $>210$ min correlated with a threefold increase in complication rates compared to the category with operative time $<59 \mathrm{~min}$.

\section{Discussion}

Eight studies we identified primarily investigated operative times in URS and correlated it to complication rates [21-28]. With a high statistical significance and large sample sizes, these studies unanimously concur that lower operative times positively correlate with lower complication rates.

Whilst URS is well known to be a safe and effective way of treating renal and ureteral stones, longer operative times are associated with an increased risk of fever, bleeding, and ureteral perforation $[17,27]$. This could be explained by larger stone volume and complex stones [34] demanding a more 
Fig. 1 PRISMA Flowchart of the included studies

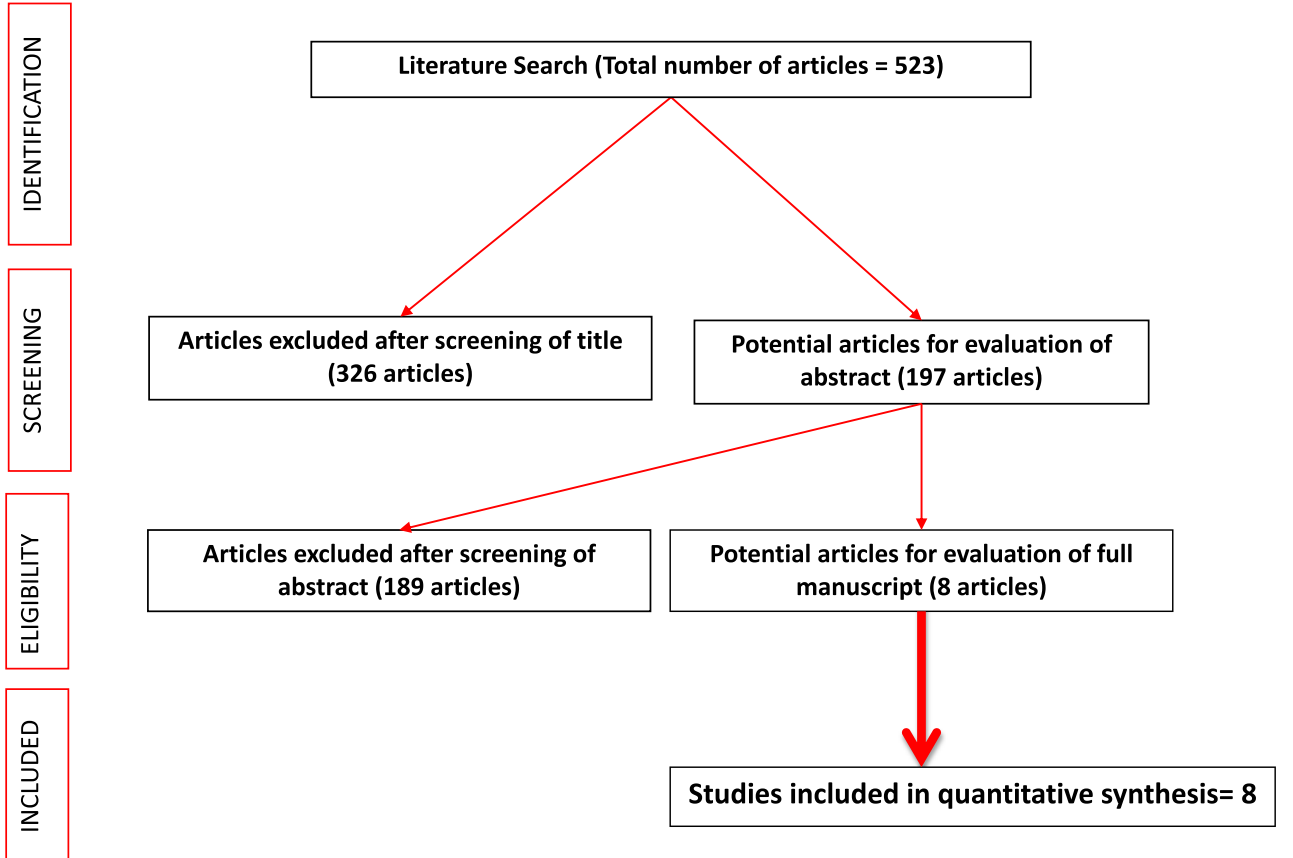

difficult and lengthy procedures [35]. Ito et al. examined operative times of 407 procedures, reviewing the total operative time and subdividing this into times before and after fragmentation [23]. The pre-fragmentation time was affected by the time it took to find the stone and thus wasn't easily predictable. The post-fragmentation time could be easily foreseen based upon the stone volume, density, absence of pre-stenting, and operator experience. The predictability of complex procedures could lead us to modify other factors that influence operative times and therefore has a direct impact upon our clinical outcomes and practice. Ozgor et al. also aimed to determine predictive factors that may reduce complication rates in URS. They reviewed 463 procedures over a 4-year period and found that operative time $>60 \mathrm{~min}$ was positively associated with infectious complications following URS [26].

Moses et al. looked specifically at unplanned returns to hospital post-URS. Those with an operative time of $>$ $120 \mathrm{~min}$ were 18 times more likely to have an unplanned return to the hospital. The majority of these were due to infection [25]. They discuss how this could be preventable by more individualized antibiotic prophylaxis and post-operative antibiotic coverage.

Somani et al. [27] reviewed all post-op complications and reviewed trends. In the CROES global study, of 11,885 patients, $874(7.3 \%)$ encountered a complication. Those with complications on average had a longer operative time at $50 \mathrm{~min}$ (range, 33-75 min) compared with $40 \mathrm{~min}$ (range, 25-60 $\mathrm{min}$ ) for those without a complication. It also highlighted that patients with complications were more likely to have had a preoperative stent and were performed in a low-volume centre. Surgeon volume and experience, therefore, seem to be an important factor in influencing operative time and complication rates.

Knipper et al. analysed the data of 2010 patients who had undergone a URS for stone treatment and stratified them into those with complications versus those without complications and found a statistically significant correlation $(p=<0.001)$ between operative time and complications [24]. Those without complications had a mean operative time of $34 \mathrm{~min}$ (range, 20-60 $\mathrm{min}$ ) compared to $45 \mathrm{~min}$ (range, 25-76 min) for those who had a complication. However, their results were not statistically significant, and they found the correlation between operative time and the occurrence of complications very weak, thus concluding that URS can be considered a safe and effective procedure even in the context of a long procedural time.

Fan et al. retrospectively reviewed 227 patients undergoing URS with holmium laser and similarly found that operative duration was found to be closely associated with the complexity of the stone, difficult anatomy, and technical experience. Infective complication rates were higher in procedures over $90 \min (p=0.026)$ [22]. Elashery et al. analysed the difference in their complication rates over a total of 15 years [21]. Unsurprisingly over this time period, operative time reduced from a mean of 75 down to $36.5 \mathrm{~min}$, and complication rates reduced synchronously ( $p=<0.001$ ) reflecting surgical volume and experience. Finally, Sugihara et al. reviewed a large sample size of 12,372 patients undergoing URS [17]. Of these, $2.39 \%$ suffered adverse events post-operatively. These patients had increasing complication rates with each 30-min increase in operative duration, which was statistically significant over $120 \min (p=<0.001)$. 


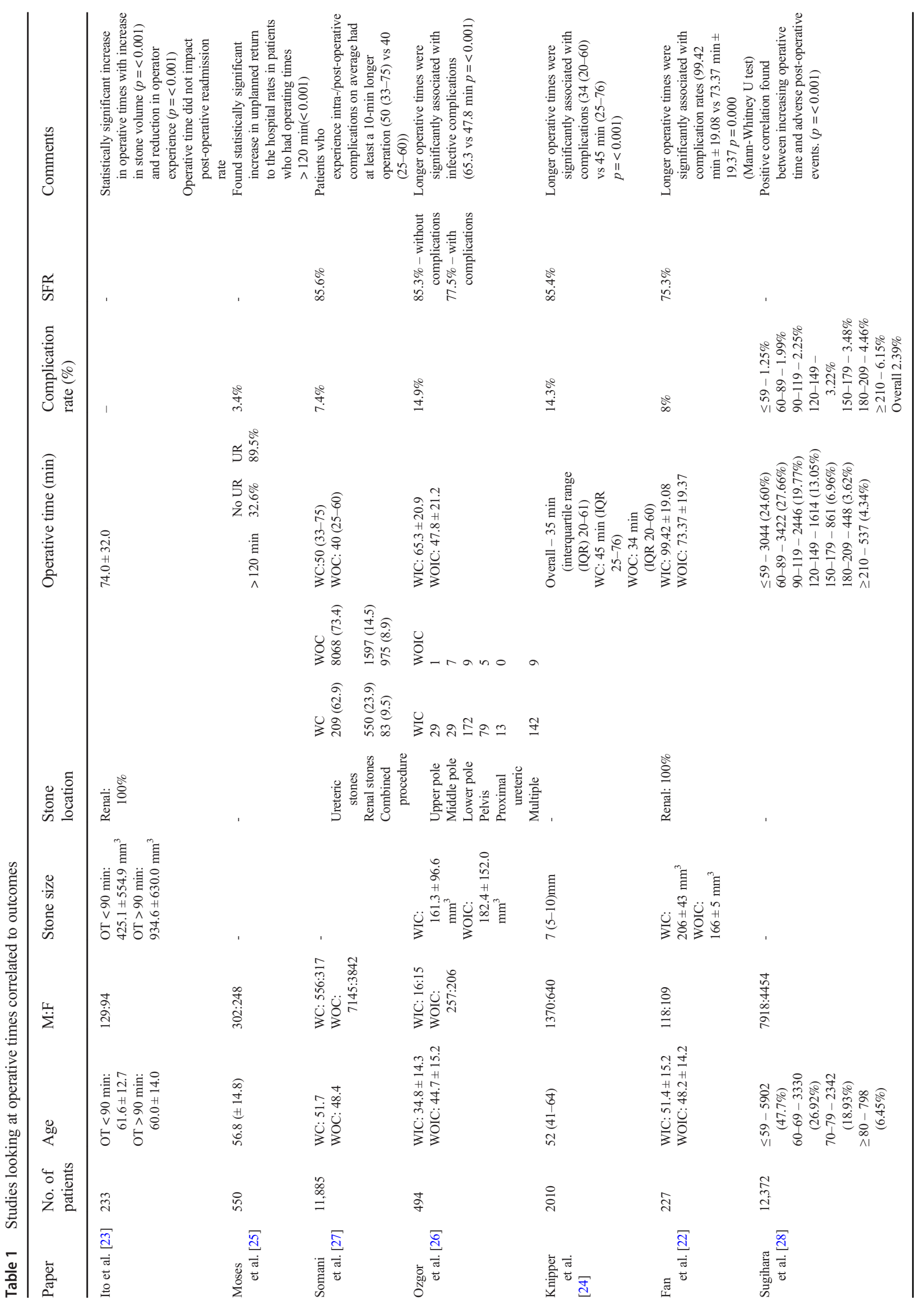


In pigs, renal cellular injury becomes evident within $1 \mathrm{~h}$ at IRPs of 20-cm $\mathrm{H}_{2} \mathrm{O}$ or greater [36]. Especially during upper tract endourological procedures, prolonged procedure times, in combination with IRPs higher than $30 \mathrm{~cm} \mathrm{H}_{2} \mathrm{O}$, have been linked to increased complication rates [37]. Of note, during URS, approximately $1 \mathrm{~mL}$ of irrigation fluid is absorbed per minute [38].

\section{Operative Times Related to Endourological Interventions}

Endourologists attempt to find new tools and techniques to reduce procedural times and thereby facilitate URS and reduce complications (Table 2).

\section{Ureteral Access Sheath}

The use of a hydrophilic-coated ureteral access sheath allows easy, multiple access to the ureter. They improve vision by establishing a continuous outflow and decreasing intrarenal pressure and therefore have been said to reduce operative time $[41,42]$. In three studies reviewed, the access sheath reduced operative times but did not affect complication rates. However, these conclusions were not statistically significant. Conversely, a recent study shows higher operative time with the use of access sheath although no statistical difference in outcomes was noted [43]. The differences could be partly accounted for by the use of access sheath in patients with larger or more complex renal stones.

\section{Pre-stenting}

Many studies have looked into the role of pre-stenting before URS [11, 14]. Stents are most commonly placed if the patient has a compromised renal function, intractable pain, or obstructed infected kidneys; however, some institutions have routinely pre-stented patients prior to URS. Similar to the UAS, they found that pre-stenting improves the stone-free rate and intraoperative complications [27]. In our review, Lumma et al. found that pre-stenting actually increased the length of the operation by 4 min yet made no difference to the complication rate [14]. Chen et al. also found the operative time to be shorter in patients who were pre-stented, on average by $15 \mathrm{~min}$, yet no significant difference in complications [11].

\section{Bilateral Surgery}

Bilateral URS can be an option to treat bilateral urolithiasis, especially in high-volume centres [44]. It allows simultaneous URS procedures rather than being staged, as the later increases the overall cumulative procedural time. It not only reduces the 


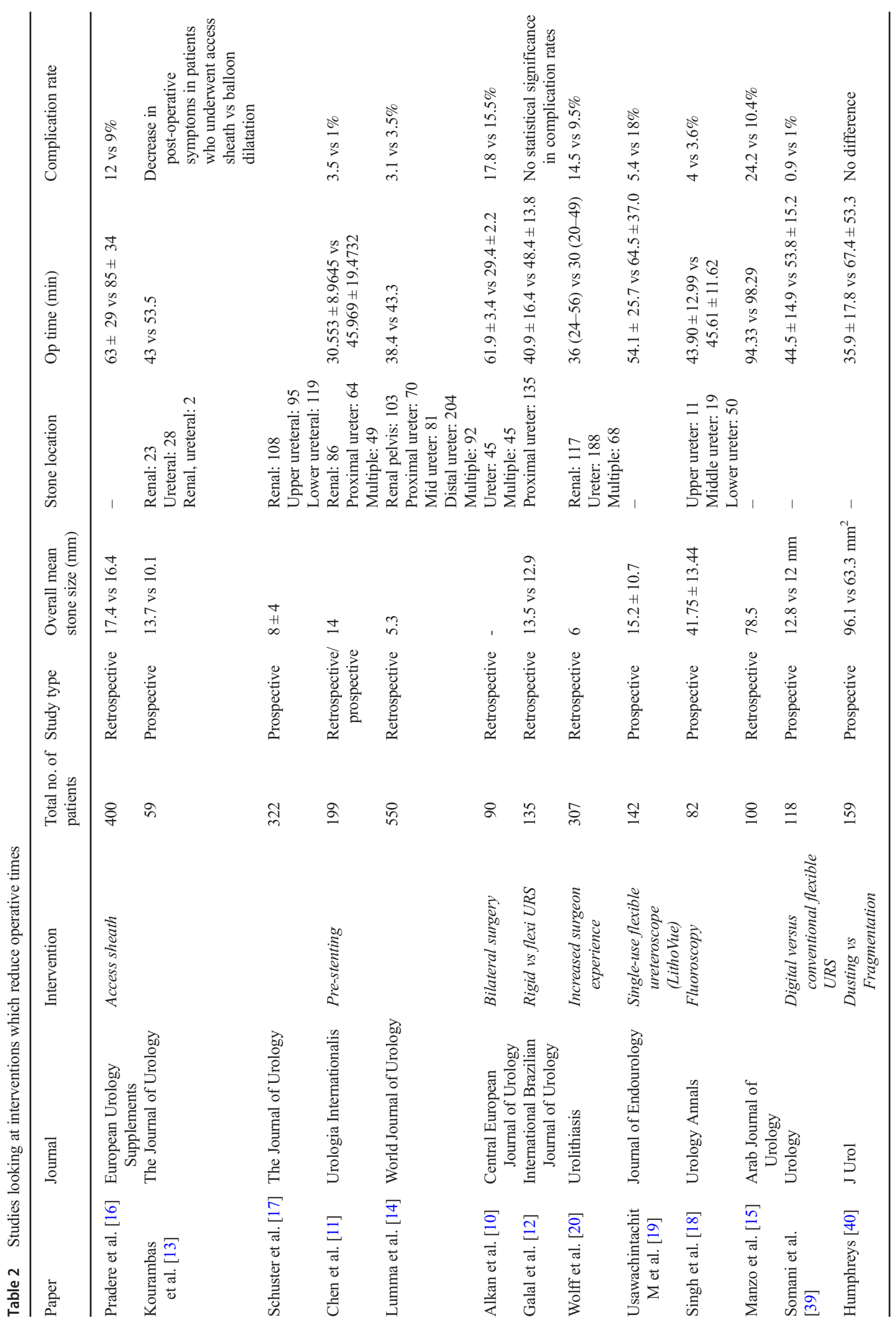


combined procedural time but could be relevant for the patient's quality of life and have huge financial savings to all healthcare systems. Nonetheless, Alkan et al. found little difference in complication rates when treating bilateral upper tract stones [10].

\section{Increased Surgeon Experience}

It may seem intuitive for increased surgeon experience correlating with a decreased operative time; however, there is limited evidence to suggest that this decreased complication rates $[45,46]$. Wolff et al. found that specialist urologists had a lower operative time and complication rate; however, neither of these were statistically significant [20]. However, other studies have shown that post-operative complications can be predicted based upon stone volume, density, absence of prestenting, and operator experience [23].

It is therefore prudent that surgical procedures are vetted beforehand so that the more complicated procedures can be identified and performed by a surgeon of appropriate experience.

\section{Single-Use Flexible Ureteroscopes}

One study in our systematic review has looked into whether single-use ureteroscopes (LithoVue) are superior to reusable scopes. Usawachintachit $\mathrm{M}$ et al. found that single-use ureteroscopes correlated with almost a 15 -min reduction in operative time [19]. The paper did not specify how LithoVue reduced operative time; however, both groups had similar complication rates.

\section{Use of Fluoroscopy}

The use of fluoroscopy is a standard aspect of all URS procedures; however, this exposes the patient and theatre staff to radiation. Two studies looked into whether ultrasound-guided URS with holmium laser lithotripsy can achieve the same results as fluoroscopy $[15,18]$. Despite the longer operative times associated with ultrasound-guided URS, complication rates between them were not significantly different, and thus the authors recommended clinicians to consider reducing radiation dosage with URS.

\section{Digital Versus Fibreoptic Ureteroscope}

The use of digital flexible ureteroscope was shown to reduce the operative time compared to fibreoptic conventional ureteroscope [39].

\section{Dusting Versus Fragmentation}

When comparing dusting with fragmentation, the former was noted to reduce the operative time significantly [40•]. Similarly, dusting and pop-dusting seem to be the new benchmark for treating large or multiple stones in a single setting without the need for a secondary procedure in most cases [47].

\section{Strengths, Limitations, and Areas of Future Research}

Operative time is positively associated with complication rates. The fewest complications appear to happen with procedural time under an hour; however, this might be biased towards straightforward URS procedures. Conversely, difficult or larger stones would have a higher risk of complication and also need longer procedural time. Hence, procedural time itself may not be the sole cause of increased complication rates. Based on our data, we would recommend limiting procedural time to under $90 \mathrm{~min}$ to reduce infectious complications and unplanned returns to the hospital. In difficult cases, a planned second-look URS might be necessary, and the patients need to be counselled accordingly.

Our review is based on published data which always has a publication bias attached to it. Future work should include a focus on the cost and quality of life of these patients [48•, 49•, $50 \bullet$. With new thulium laser and smaller scopes promising to reduce the operative times further, the landscape of URS will change further and lead to a wider uptake and use in difficult patients $[51,52 \bullet]$.

\section{Conclusion}

Longer procedural time seems to be associated with a higher risk of post-ureteroscopy complications. The use of ureteral access sheath, preoperative stent, and surgeon experience all influence procedural times. The size and complexity of stone and patient risk factors also need to be understood and stratified for planning ureteroscopy, patient counselling, and shared decision-making. Ultimately the principle of 'ALARA - as low as reasonably achievable' and keeping the procedural time as short as possible would lower complication rates and seem to be a good strategy provided the SFR is not compromised.

\section{Compliance with Ethical Standards}

Conflict of Interest The authors declare that they have no conflict(s) of interest.

Human and Animal Rights and Informed Consent This article does not contain any studies with human or animal subjects performed by any of the authors. 
Open Access This article is licensed under a Creative Commons Attribution 4.0 International License, which permits use, sharing, adaptation, distribution and reproduction in any medium or format, as long as you give appropriate credit to the original author(s) and the source, provide a link to the Creative Commons licence, and indicate if changes were made. The images or other third party material in this article are included in the article's Creative Commons licence, unless indicated otherwise in a credit line to the material. If material is not included in the article's Creative Commons licence and your intended use is not permitted by statutory regulation or exceeds the permitted use, you will need to obtain permission directly from the copyright holder. To view a copy of this licence, visit http://creativecommons.org/licenses/by/4.0/.

\section{References}

Papers of particular interest, published recently, have been highlighted as:

- Of importance

1. Geraghty RM, Jones P, Somani BK. Worldwide trends of urinary stone disease treatment over the last two decades: a systematic review. J Endourol. 2017;31(6):547-56. https://doi.org/10.1089/ end.2016.0895.

2. Pietropaolo A, Proietti S, Geraghty R, Skolarikos A, Papatsoris A, Liatsikos E, et al. Trends of 'urolithiasis: interventions, simulation, and laser technology' over the last 16 years (2000-2015) as published in the literature (PubMed): a systematic review from European section of Uro-technology (ESUT). World J Urol. 2017;35(11):1651-8. https://doi.org/10.1007/s00345-017-2055-z.

3. Geraghty RM, Proietti S, Traxer O, Archer M, Somani BK. Worldwide impact of warmer seasons on the incidence of renal colic and kidney stone disease: evidence from a systematic review of literature. J Endourol. 2017;31(8):729-35. https://doi.org/10. 1089/end.2017.0123.

4. Rob S, Bryant T, Wilson I, Somani BK. Ultra-low-dose, low-dose, and standard-dose CT of the kidney, ureters, and bladder: is there a difference? Results from a systematic review of the literature. Clin Radiol. 2017;72(1):11-5. https://doi.org/10.1016/j.crad.2016.10. 005.

5. Wong Y, Cook P, Roderick P, Somani BK. Metabolic syndrome and kidney stone disease: a systematic review of literature. J Endourol. 2016;30(3):246-53. https://doi.org/10.1089/end.2015.0567 Comprehensive review showing a correlation of metabolic syndrome and kidney stones.

6. Turk C, Petrik A, Sarica K, Seitz C, Skolarikos A, Straub M, et al. EAU guidelines on interventional treatment for Urolithiasis. Eur Urol. 2016;69(3):475-82. https://doi.org/10.1016/j.eururo.2015. 07.041 .

7. Ghosh A, Oliver R, Way C, White L, Somani BK. Results of daycase ureterorenoscopy (DC-URS) for stone disease: prospective outcomes over 4.5 years. World J Urol. 2017;35(11):1757-64. https://doi.org/10.1007/s00345-017-2061-1.

8. Somani BK, Dellis A, Liatsikos E, Skolarikos A. Review on diagnosis and management of urolithiasis in pregnancy: an ESUT practical guide for urologists. World J Urol. 2017;35(11):1637-49. https://doi.org/10.1007/s00345-017-2037-1.

9. Somani BK, Moseley H, Eljamel MS, Nabi G, Kata SG. Photodynamic diagnosis (PDD) for upper urinary tract transitional cell carcinoma (UT-TCC): evolution of a new technique. Photodiagn Photodyn Ther. 2010;7(1):39-43. https://doi.org/10. 1016/j.pdpdt.2009.12.005.
10. Alkan E, Turan M, Ozkanli O, Avci E, Basar MM, Acar O, et al. Combined ureterorenoscopy for ureteral and renal calculi is not associated with adverse outcomes. Cent European J Urol. 2015;68(2):187-92. https://doi.org/10.5173/ceju.2015.538.

11. Chen H, Chen G, Zhu Y, Yang Z, Xiong C, Pan Y. Analysis of prestenting on outcomes of flexible ureteroscopy for upper urinary urolithiasis: a historical control study. Urol Int. 2019;102(2):17580. https://doi.org/10.1159/000494362.

12. Galal EM, Anwar AZ, El-Bab TK, Abdelhamid AM. Retrospective comparative study of rigid and flexible ureteroscopy for treatment of proximal ureteral stones. Int Braz J Urol. 2016;42(5):967-72. https://doi.org/10.1590/s1677-5538.Ibju.2015.0644.

13. Kourambas J, Byrne RR, Preminger GM. Does a ureteral access sheath facilitate ureteroscopy? J Urol. 2001;165(3):789-93.

14. Lumma PP, Schneider P, Strauss A, Plothe KD, Thelen P, Ringert $\mathrm{RH}$, et al. Impact of ureteral stenting prior to ureterorenoscopy on stone-free rates and complications. World J Urol. 2013;31(4):8559. https://doi.org/10.1007/s00345-011-0789-6.

15. Manzo BO, Lozada E, Manzo G, Sanchez HM, Gomez F, Figueroa A, et al. Radiation-free flexible ureteroscopy for kidney stone treatment. Arab J Urol. 2019;17(3):200-5. https://doi.org/10.1080/ 2090598x.2019.1606381.

16. Pradere B, Peyronnet B, Khene ZE, Freton L, Alimi Q, Mathieu R, et al. Perioperative outcomes of flexible ureterorenoscopy for urolithiasis using the sheathless technique: a comparative study. Eur Urol Suppl. 2019;18(1):e2024-5. https://doi.org/10.1016/S15699056(19)31466-6.

17. Schuster TG, Hollenbeck BK, Faerber GJ, Wolf JS Jr. Complications of ureteroscopy: analysis of predictive factors. $\mathrm{J}$ Urol. 2001;166(2):538-40. https://doi.org/10.1016/s00225347(05)65978-2.

18. Singh V, Purkait B, Sinha RJ. Prospective randomized comparison between fluoroscopy-guided ureteroscopy versus ureteroscopy with real-time ultrasonography for the management of ureteral stones. Urol Ann. 2016;8(4):418-22. https://doi.org/10.4103/0974-7796. 192098.

19. Usawachintachit M, Isaacson DS, Taguchi K, Tzou DT, Hsi RS, Sherer BA, et al. A prospective case-control study comparing LithoVue, a single-use, flexible disposable ureteroscope, with flexible, reusable fiber-optic ureteroscopes. J Endourol. 2017;31(5): 468-75. https://doi.org/10.1089/end.2017.0027.

20. Wolff I, Lebentrau S, Miernik A, Ecke T, Gilfrich C, Hoschke B, et al. Impact of surgeon's experience on outcome parameters following ureterorenoscopic stone removal. Urolithiasis. 2019;47(5): 473-9. https://doi.org/10.1007/s00240-018-1073-7.

21. Elashry OM, Elgamasy AK, Sabaa MA, Abo-Elenien M, Omar MA, Eltatawy HH, et al. Ureteroscopic management of lower ureteric calculi: a 15-year single-centre experience. BJU Int. 2008;102(8):1010-7. https://doi.org/10.1111/j.1464-410X.2008. 07747.x.

22. Fan S, Gong B, Hao Z, Zhang L, Zhou J, Zhang Y, et al. Risk factors of infectious complications following flexible ureteroscope with a holmium laser: a retrospective study. Int J Clin Exp Med. 2015;8(7):11252-9.

23. Ito H, Kuroda S, Kawahara T, Makiyama K, Yao M, Matsuzaki J. Clinical factors prolonging the operative time of flexible ureteroscopy for renal stones: a single-center analysis. Urolithiasis. 2015;43(5):467-75. https://doi.org/10.1007/s00240015-0789-x.

24. Knipper S, Tiburtius C, Gross AJ, Netsch C. Is prolonged operation time a predictor for the occurrence of complications in ureteroscopy? Urol Int. 2015;95(1):33-7. https://doi.org/10.1159/ 000367811.

25. Moses RA, Ghali FM, Pais VM Jr, Hyams ES. Unplanned hospital return for infection following ureteroscopy - can we identify 
modifiable risk factors? J Urol. 2016;195(4 Pt 1):931-6. https://doi. org/10.1016/j.juro.2015.09.074.

26. Ozgor F, Sahan M, Cubuk A, Ortac M, Ayranci A, Sarilar O. Factors affecting infectious complications following flexible ureterorenoscopy. Urolithiasis. 2019;47(5):481-6. https://doi.org/ 10.1007/s00240-018-1098-y.

27. Somani BK, Giusti G, Sun Y, Osther PJ, Frank M, De Sio M, et al. Complications associated with ureterorenoscopy (URS) related to treatment of urolithiasis: the Clinical Research Office of Endourological Society URS Global study. World J Urol. 2017;35(4):675-81. https://doi.org/10.1007/s00345-016-1909-0.

28. Sugihara T, Yasunaga $H$, Horiguchi $H$, Nishimatsu H, Kume H, Ohe $\mathrm{K}$, et al. A nomogram predicting severe adverse events after ureteroscopic lithotripsy: 12372 patients in a Japanese national series. BJU Int. 2013;111(3):459-66. https://doi.org/10.1111/j. 1464-410X.2012.11594.x.

29. Duchman KR, Pugely AJ, Martin CT, Gao Y, Bedard NA, Callaghan JJ. Operative time affects short-term complications in total joint arthroplasty. J Arthroplast. 2017;32(4):1285-91. https:// doi.org/10.1016/j.arth.2016.12.003.

30. Jackson TD, Wannares JJ, Lancaster RT, Rattner DW, Hutter MM. Does speed matter? The impact of operative time on outcome in laparoscopic surgery. Surg Endosc. 2011;25(7):2288-95. https:// doi.org/10.1007/s00464-010-1550-8.

31. Sugihara T, Yasunaga H, Horiguchi H, Fujimura T, Nishimatsu H, Kume H, et al. Longer operative time is associated with higher risk of severe complications after percutaneous nephrolithotomy: analysis of 1511 cases from a Japanese nationwide database. Int J Urol. 2013;20(12):1193-8. https://doi.org/10.1111/iju.12157.

32. Higgins JP, Green S, editors. Cochrane handbook for systematic reviews of interventions. Chichester: John Wiley \& Sons, Ltd; 2008. (accessed 03/08/2018

33. Moher D, Liberati A, Tetzlaff J, Altman DG. Preferred reporting items for systematic reviews and meta-analyses: the PRISMA statement. PLoS Med. 2009;6(7):e1000097. https://doi.org/10.1371/ journal.pmed.1000097.

34. Kuroda S, Ito H, Sakamaki K, Tabei T, Kawahara T, Fujikawa A, et al. A new prediction model for operative time of flexible ureteroscopy with lithotripsy for the treatment of renal stones. PLoS One. 2018;13(2):e0192597. https://doi.org/10.1371/journal. pone. 0192597.

35. Sorokin I, Cardona-Grau DK, Rehfuss A, Birney A, Stavrakis C, Leinwand $\mathrm{G}$, et al. Stone volume is best predictor of operative time required in retrograde intrarenal surgery for renal calculi: implications for surgical planning and quality improvement. Urolithiasis. 2016;44(6):545-50. https://doi.org/10.1007/s00240-016-0875-8.

36. Fung LC, Atala A. Constant elevation in renal pelvic pressure induces an increase in urinary $\mathrm{N}$-acetyl-beta-D-glucosaminidase in a nonobstructive porcine model. J Urol. 1998;159(1):212-6.

37. Tokas T, Herrmann TRW, Skolarikos A, Nagele U. Pressure matters: intrarenal pressures during normal and pathological conditions, and impact of increased values to renal physiology. World J Urol. 2018;37:125-31. https://doi.org/10.1007/s00345-018-2378-4.

38. Cybulski P, Honey RJ, Pace K. Fluid absorption during ureterorenoscopy. J Endourol. 2004;18(8):739-42. https://doi.org/ 10.1089/end.2004.18.739.

39. Somani BK, Al-Qahtani SM, de Medina SD, Traxer O. Outcomes of flexible ureterorenoscopy and laser fragmentation for renal stones: comparison between digital and conventional ureteroscope. Urology. 2013;82(5):1017-9.

40. Humphreys MR, Shah OD, Monga M, Chang YH, Krambeck AE, Sur RL, et al. Dusting versus basketing during ureteroscopy - which technique is more efficacious? A prospective musticenter trial from the EDGE Research Consortium. J Urol. 2018;199(5):

1272-6 This study shows that dusting is more time efficient than fragmentation for treatment of stone disease.

41. L'Esperance JO, Ekeruo WO, Scales CD Jr, Marguet CG, Springhart WP, Maloney ME, et al. Effect of ureteral access sheath on stone-free rates in patients undergoing ureteroscopic management of renal calculi. Urology. 2005;66(2):252-5. https://doi.org/ 10.1016/j.urology.2005.03.019.

42. Stern JM, Yiee J, Park S. Safety and efficacy of ureteral access sheaths. J Endourol. 2007;21(2):119-23. https://doi.org/10.1089/ end.2007.9997.

43. Lima A, Reeves T, Geraghty R, Pietropaolo A, Whitehurst L, Somani BK. Impact of ureteral access sheath on renal stone treatment: prospective comparative non-randomised outcomes over a 7 year period. World J Urol. 2019:1-5. https://doi.org/10.1007/ s00345-019-02878-5.

44. Geraghty RM, Rai BP, Jones P, Somani BK. Bilateral simultaneous ureteroscopic (BS-URS) approach in the management of bilateral urolithiasis is a safe and effective strategy in the contemporary eraevidence from a systematic review. Curr Urol Rep. 2017;18(2):11. https://doi.org/10.1007/s11934-017-0660-4.

45. Johans C, Smelser W, DeRoche C, Campbell J, Cummings J. Assessment of patient and surgical variables including residency training level on adverse events after ureteroscopy for ureteral stones: a multivariate analysis. J Endourol. 2018;32(2):144-7. https://doi.org/10.1089/end.2017.0757.

46. Netsch C, Knipper AS, Orywal AK, Tiburtius C, Gross AJ. Impact of surgical experience on stone-free rates of ureteroscopy for single urinary calculi of the upper urinary tract: a matched-paired analysis of 600 patients. J Endourol. 2015;29(1):78-83. https://doi.org/10. 1089/end.2014.0301.

47. Pietropaolo A, Jones P, Whitehurst L, Somani BK. Role of 'dusting and pop-dusting' using a high-powered (100W) laser machine in the treatment of large stones $(>15 \mathrm{~mm})$ : prospective outcomes over 16 months. Urolithiasis. 2019;47(4):391-4.

48. Geraghty RM, Jones P, Herrmann TRW, Aboumarzouk O, Somani BK. Ureteroscopy is more cost effective than shock wave lithotripsy for stone treatment: systematic review and meta-analysis. World J Urol. 2018;36(11):1783-93. https://doi.org/10.1007/s00345-0182320-9 This review shows that ureteroscopy is more cost effective than shockwave lithotripsy for treatment of kidney stones.

49. New F, Somani BK. A complete world literature review of quality of life (QOL) in patients with kidney stone disease (KSD). Curr Urol Rep. 2016;17(12):88-6. https://doi.org/10.1007/s11934-0160647-6.

50. Somani BK, Robertson A, Kata SG. Decreasing the cost of flexible ureterorenoscopic procedures. Urology. 2011;78(3):528-30. https://doi.org/10.1016/j.urology.2010.12.073.

51. Ho A, Sarmah P, Bres-Niewada E, Somani BK. Ureteroscopy for stone disease: expanding roles in the modern era. Cent European J Urol. 2017;70(2):175-8. https://doi.org/10.5173/ceju.2017.1343.

52. Kronenberg P, Traxer O. The laser of the future: reality and expectations about the new thulium fiber laser-a systematic review. Transl Androl Urol. 2019;8(Suppl 4):S398-s417. https://doi.org/10. 21037/tau.2019.08.01 One of the most comprehensive systematic reviews on thulium laser for stone disease.

Publisher's Note Springer Nature remains neutral with regard to jurisdictional claims in published maps and institutional affiliations. 